\title{
Ako for Niños: An animated children's series bridging migrant participation and intercultural co-design to bring meaningful Tikanga to Tauiwi
}

\author{
Keywords \\ Co-design, Educational Animation, Intercultural Literacy, Participatory Storytelling, Tikanga Māori.
}

This presentation advances a case study for an ongoing intercultural animation project which seeks to meaningfully educate New Zealand Tauiwi (the country's diverse groups, including migrants and refugees) on the values, customs and protocols (Tikanga) of Māori (the indigenous people of Aotearoa New Zealand). Ako For Niños ('education for children'), implemented by a migrant social services organisation and media-design team, introduces Latin American Tauiwi to Tikanga through an animated children's series, developed with a community short story writing competition and co-design with a kaitiaki (Māori guardian/advisor). Māori are recognised in Te Tiriti o Waitangi (the founding document of New Zealand) as partners with Pākeha (European New Zealanders), and Māori knowledge and Tikanga are important to society and culture in Aotearoa. Notwithstanding, there has been a historic lack of attention paid to developing meaningful understandings of Māori perspectives for New Zealand Tauiwi. Ako For Niños endeavours to address current shortages of engaging resources on Māori worldviews for Tauiwi communities, create opportunities for Tauiwi to benefit from Māori epistemologies, and foster healthy community relationships between Māori and Latin American Tauiwi. Through the project's short story competition, Tauiwi were given definitions of Tikanga through a social media campaign, then prompted to write a children's tale based on one of these in their native language. This encouraged Tauiwi to gain deeper comprehension of Māori values, and interpret Tikanga into their own expressions. Three winning entries were selected, then adapted into stop-motion and 2D animations. By converting the stories into aesthetically pleasing animated episodes, the Tikanga and narratives could be made more captivating for young audiences and families, appealing to the senses and emotions through visual storytelling, sound-design, and music. The media-design team worked closely with a kaitiaki during this process to better understand and communicate the Tikanga, adapting and co-designing the narratives in a culturally safe process. This ensured Māori knowledge, values, and interests were disseminated in correct and respectful ways. We argue for the importance of creative participation of Tauiwi, alongside co-design with Māori to produce educational intercultural design projects on Māori worldviews. Creative participation encourages new cultural knowledge to be imaginatively transliterated into personal interpretations and expressions of Tauiwi, allowing indigenous perspectives to be made more meaningful. This meaningful engagement with Māori values, which are more grounded in relational and human-centred concepts, can empower Tauiwi to feel more cared for and interconnected with their new home and culture. Additionally, co-design with Māori can help to honour Te Tiriti, and create spaces where Tauiwi, Pākeha and Māori interface in genuine partnership with agency (rangatiratanga), enhancing the credibility and value of outcomes. This session unpacks the contexts informing, and methods undertaken to develop the series, presenting current outcomes and expected directions (including a screening and exhibition). We will also highlight potential for the methodology to be applied in new ways in future, such as with other Tauiwi communities, different cultural knowledge, and increased collaborative co-design with Māori. 